\title{
RIQUEZA Y CULTURA ECONÓMICA EN LA ESPAÑA DEL SIGLO XVI. LA PREDICACIÓN DE TOMÁS DE VILLANUEVA EN TIEMPOS DE FRANCISCO DE VITORIA
}

\author{
WEALTH AND ECONOMIC CULTURE IN SPANISH SIXTEENTH \\ CENTURY. THE PREACHING OF TOMÁS DE VILLANUEVA \\ IN TIMES OF FRANCISCO DE VITORIA
}

\author{
CLEMENTE LÓPEZ GONZÁLEZ \\ Universidad Francisco de Vitoria \\ JosÉ IGNACIO RUIZ RODRÍGUEZ \\ Universidad de Alcalá
}

Recibido: 30/07/2019 Aceptado: 23/09/2019

\section{RESUMEN}

A comienzos del siglo XVI la cultura española estaba experimentando una profunda transformación. El paso de la cultura medieval a la cultura moderna corría parejo a la creación del Estado moderno y a la difusión de la economía capitalista gracias a la riqueza generada por la llegada de los metales preciosos y el comercio con las Indias. La sociedad española se debatía entre lo tradicional y lo nuevo. Los códigos de conducta y los valores heredados del pasado eran cuestionados, cuando no sustituidos, por otros nuevos.

En este contexto uno de los temas que más reflejan ese mundo cambiante es el del ascenso de un grupo humano en la hasta entonces rígida jerarquía social. Ese grupo era el de las personas que se estaban enriqueciendo rápidamente gracias al cambio económico que se estaba operando. La palanca que les impulsaba en su acenso social era la riqueza que acumulaban, la cual también les convertía en un modelo para la imitación de muchos otros. 
Sin embargo, la acumulación de ganancias generaba muchos recelos e, incluso, rechazo para la moral tradicional defendida y predicada por la Iglesia Católica. Además, la conducta y actitudes de ese grupo humano no solo eran censurables para la moral de la época, sino que también, en tanto que podían ser contagiosas para el resto de la sociedad, debían ser denunciadas y, en la medida de lo posible, reconducidas hacia valores más consonantes con la tradición de la Iglesia.

Es en este contexto en el que se encuadra la predicación de Tomás de Villanueva contra los peligros morales de la riqueza y contra las actitudes y conducta de los ricos. El conocimiento de los contenidos de la predicación de uno de los más excelsos predicadores de la España del siglo XVI se revela como un valioso acercamiento a la cultura económica de la época. A diferencia de teólogos y académicos, los predicadores centraban sus esfuerzos no en profundizar en el conocimiento teórico de los grandes temas, sino en persuadir a sus fieles de no caer en conductas y actitudes contrarias a la moral o, si ya habían caído, de cambiar su estilo de vida. Por esta razón, por medio de la lectura de los textos conservados de los predicadores, podemos descubrir la mentalidad, las creencias, las ideas de la gente de la época.

Santo Tomás de Villanueva nos revela en sus sermones su gran conocimiento del pensamiento de la Iglesia sobre la riqueza, fruto de su formación universitaria en Alcalá. Nos muestra, al mismo tiempo, su fidelidad al magisterio eclesial, actualizado en España por Francisco de Vitoria y la Escuela de Salamanca. Pero, sin duda, lo más revelador de la predicación de nuestro santo es su agudeza para captar la mentalidad y contradicciones de la conducta de los ricos y de los que, sin serlo, compartían su avaricia y codicia, así como su capacidad para remover conciencias y provocar cambios de conductas. Sin duda alguna, la burguesía, de la cual estos nuevos ricos fueron precursores, consolidaría su ascenso social en los siglos posteriores. Pero eso no significa que en su horizonte cultural no quedara incluida de una u otra manera la conciencia de una responsabilidad social hacia los más desfavorecidos. Algo que Tomás de Villanueva y otros muchos predicadores no dejaron nunca de reclamar.

Palabras clave: España en el siglo XVI, oratoria sagrada, riqueza, Tomás de Villanueva.

\section{ABSTRACT}

At the beginning of the 16th century, Spanish culture was undergoing a deep transformation. The transition from medieval to modern culture was running on par with the creation of the modern state and the spread of the capitalist economy, thanks to the wealth generated by the arrival of precious metals and trade with the Indies. Spanish 
society was torn between the traditional and the new. The codes of conduct and values inherited from the past were questioned when not replaced by new ones.

In this context, one of the issues that reflect that changing world the most is the rise of a human group in the hitherto rigid social hierarchy. It was the group of people who were quickly getting rich, thanks to the economic change that was taking place. The wealth they accumulated was the lever driving them in their social ascent, making them at the same time a model for imitation of many others.

However, the accumulation of profits also generated many misgivings and reject by the traditional morals defended and preached by the Catholic Church. In addition, the behavior and attitudes of that human group were not only objectionable for the morals of the time, but also, insofar as they could be contagious for the rest of society, they should be denounced and, as far as possible, redirected to values more consistent with the tradition of the Church.

It is in this context that Tomás de Villanueva's preaching is framed against the moral dangers of wealth and against the attitudes and behavior of the rich. The knowledge of the contents of the preaching of one of the most excellent preachers of the sixteenth-century Spain, is revealed as a valuable approach to the economic culture of the time. Unlike theologians and academics, the preachers focused their efforts not on deepening the theoretical knowledge of the great themes but on persuading their faithful not to fall into behaviors and attitudes contrary to morals or, if they had already fallen, to change their lifestyle. For this reason, from reading the preserved texts of the preachers we can discover the mentality, beliefs and ideas of the people of the time.

Santo Tomás de Villanueva, reveals to us in his sermons his great knowledge of the Church's thought about wealth as a result of his university education in Alcalá and, at the same time, his fidelity to the ecclesial teaching, updated in Spain by Francisco de Vitoria and the School of Salamanca. But, without a doubt, the most telling thing about the preaching of our saint is his keenness to capture the mentality and contradictions of the behavior of the rich and of those who, without being so, shared their greed and avarice and their ability to remove consciences and provoke behavior changes. Without a doubt, the bourgeoisie, of which these were its precursors, would consolidate its social ascent in later centuries. But that does not mean that in their cultural horizon the awareness of a social responsibility towards the most disadvantaged will not be included in one way or another. Something that Tomás de Villanueva and many other preachers never stopped proclaiming.

Keywords: sacred oratory, Spain in the sixteenth century, Tomás de Villanueva, wealth. 


\section{INTRODUCCIÓN}

A comienzos del siglo XVI, la sociedad española estaba experimentando una profunda transformación vinculada al paso de una cosmovisión medieval a una cosmovisión moderna y expresada en lo cultural por el movimiento humanista y renacentista. De la misma manera, esta transformación cultural se correspondía, en lo político, con la aparición del Estado moderno y, en lo económico, con la expansión de una economía capitalista de corte mercantilista. Naturalmente, en el seno de aquella sociedad, estas transformaciones generaban tensiones internas que se manifestaban en posturas contrapuestas entre los partidarios de la defensa de la tradición y los que abrazaban la modernidad.

Uno de los planos en los que mejor se puede apreciar estas transformaciones es el de la cultura económica. ${ }^{1}$ Pero, para adentrarnos en ese campo de estudio es necesario utilizar fuentes que no necesariamente respondan a lo que entendemos desde el presente de la lógica económica actual de oferta y demanda. Creemos que, entre esas fuentes, destacan, en el siglo XVI, los sermones de los predicadores. Estos sermones, si bien es verdad que fueron aplicados de forma oral, nos han llegado en gran número a través de las transcripciones escritas. Dentro de ese corpus documental, resulta especialmente idóneo para el presente trabajo la recopilación de los sermones de Santo Tomás de Villanueva recientemente publicada. ${ }^{2} \mathrm{Si}$ la predicación, en términos generales, es una fuente muy valiosa para el conocimiento de la cultura y la mentalidad de una época, ${ }^{3}$ la predicación de Santo Tomás de Villanueva, por su magnitud y por la altura intelectual y moral de su autor, resulta una fuente privilegiada para adentrarnos a nuestro pasado.

Dentro del amplio abanico de elementos que componen la cultura económica de una época, uno de los temas clave es la idea que se tiene de la riqueza y la actitud social hacia los ricos y su enriquecimiento. El objetivo de nuestra investigación es, mediante el análisis del contenido de los sermones de uno de los más grandes predicadores del siglo XVI, verificar tres hipótesis. La primera

1 Entendemos cultura económica como el conjunto de ideas y creencias que comparte mayoritariamente una sociedad sobre la dimensión económica de la acción colectiva. O como lo define Berger, "el medio ambiente cultural en el que están insertas las instituciones y los procesos económicos". Peter L. Berger, “Observaciones acerca de la cultura económica”, Estudios Públicos, 40 (1990), 14.

2 En los últimos años, un equipo de agustinos ha realizado un importante trabajo de recopilación y edición de los textos latinos del santo y su traducción al español. El resultado ha sido la publicación de las Obras completas de Tomás de Villanueva en la BAC. Véase el Estudio preliminar de Laureano Manrique que figura en el Tomo I. de las Obras Completas de Santo Tomás de Villanueva. Obras Completas, Tomo I (Madrid: BAC, 2010), XI-XXXIX.

3 Félix Herrero Salgado y Miguel Ángel Núñez Beltrán, Predicadores y sermones en España (Siglos XVI-XX) (Madrid: Fundación Universitaria Española, 2014), 12 y ss. 
afirma que el pensamiento de nuestro santo sobre la riqueza se identificaba plenamente con la tradición de la Iglesia, tradición de la que de modo paralelo también se alimentaba la Escuela de Salamanca. ${ }^{4}$ La segunda es que Tomás de Villanueva, gracias a la formación recibida en la Universidad de Alcalá, fue capaz de integrar el humanismo renacentista y la tradición escolástica en una oratoria perfectamente adaptada a su audiencia; comunicaba con un lenguaje sencillo, diferente al de los filósofos y teólogos, las mismas ideas que se estudiaban y debatían en las universidades sin desdibujar su contenido y significado. ${ }^{5}$ La última hipótesis establece que, desde el contenido de la predicación de nuestro autor, se pueden conocer con más profundidad las mentalidades y las actitudes sociales de una España en la que latían grandes tensiones. Estas tensiones eran consecuencia de la fractura social provocada por el empuje de una modernidad que venía de la mano del creciente desarrollo de una economía dineraria.

Nuestra intención ha sido que el análisis de los sermones dedicados al tema de la riqueza fuera lo más exhaustivo posible. Hemos centrado nuestra atención en determinar cuál era el origen de la riqueza, qué diferencia había entre su dimensión moral y económica, cuál era la finalidad de su uso y a qué consecuencias llevaba su mal empleo. En definitiva, la idea de riqueza que tenía un predicador que también fue profesor universitario, teólogo y arzobispo, y que se apoyaba en la tradición moral de la Iglesia y en la tradición intelectual de Occidente. Como predicador, utilizó un lenguaje distinto al de la cátedra universitaria para llegar a la gente. De este modo, por una parte, pretendía denunciar los abusos morales en los que podían incurrir los nuevos grupos sociales que estaban dedicados a la actividad mercantil. Por otra, trataba de movilizar las voluntades contra los desequilibrios sociales en la distribución de la riqueza.

Dentro de los nuevos grupos sociales generados por la modernidad, el de los mercaderes es objeto especial de nuestra atención. La razón de ello es que ellos eran, a comienzos del siglo XVI, los portadores de una nueva mentalidad capitalista, caracterizada por la búsqueda racional del beneficio económico y el deseo de autonomía moral en sus prácticas.

4 Aunque la tradición intelectual de la Universidad de Salamanca venía de tiempo atrás, fue con la llegada de Francisco de Vitoria a la cátedra de Teología y su explicación de esta disciplina no a partir de las Sentencias de Pedro Lombardo, sino a partir de la Summa de Santo Tomás de Aquino cuando se revolucionarían las aulas de tan insigne universidad y se crearía una escuela con identidad propia. Por otra parte, Tomás de Villanueva también conocía en profundidad el pensamiento del Aquinate. Sobre la Escuela de Salamanca véase Miguel Anxo Pena González, "Aproximación histórica al concepto Escuela de Salamanca", Salmanticensis, 52 (2005), 50 y ss.

5 Ésta ha sido la razón por la que hemos preferido acercar al lector textos completos de Tomás de Villanueva en vez de limitarnos a ofrecer un resumen o una breve referencia. 


\section{LA IDEA DE RIQUEZA A COMIENZOS DEL SIGLO XVI Y SUS ORÍ- GENES}

A comienzos del siglo XVI, la idea de riqueza comúnmente admitida en todo el mundo occidental era la desarrollada por la Iglesia a lo largo de la Edad Media. ${ }^{6}$ Se inspiraba fundamentalmente en la Biblia, pero también en el pensamiento grecolatino y en la enseñanza de los Padres de la Iglesia. Sin embargo, había importantes diferencias entre la moral escolástica y las ideas de los primeros cristianos. El primitivo ideal cristiano de la pobreza había dado paso a una visión de la riqueza en la que lo importante no era su posesión sino su uso. Riqueza y pobreza eran de designio divino y Dios había asociado un fin a ambas. ${ }^{7}$ Otra cuestión era la del enriquecimiento. Para la Iglesia medieval, la lógica económica no tenía una finalidad de crecimiento (que es lo propio de un sistema capitalista), sino de búsqueda de un orden armónico. Se consideraba que el mundo estaba provisto de abundantes bienes para sus pobladores. Pero el reparto de esos bienes no había sido equitativo. Precisamente por esa razón, el enriquecimiento que algunos habían logrado llevaba consigo la obligación de un reparto a los desfavorecidos, cuya vía era la práctica de la caridad. Una práctica a la que la Iglesia llamaba insistentemente y que se convertía en obligación para todos los cristianos.

Por otra parte, para una mentalidad que se basaba en el orden social y buscaba un equilibrio en lo económico (como era la mentalidad medieval), no correspondía a las personas cambiar la posición que tenían asignada en la jerarquía social. El enriquecimiento venía de manera natural y se derivaba de los derechos de conquista o como recompensa por los méritos adquiridos. Su finalidad no era tanto la riqueza sino el poder y triunfo de una comunidad articulada en el seno de una civilización en expansión. ${ }^{8}$ La adquisición de tesoros o botines se derivaba más de una función guerrera y heroica que mercantil. ${ }^{9}$ Por otra parte, el patrimonio feudal estaba fuera de la lógica de la propiedad privada. Cumplía una función social de condominio mediante el cual una parte iba para el sostenimiento del guerrero y para continuar su función, mientras que la otra parte iba para el productor directo. El mecanismo en su conjunto constituía un régimen

\footnotetext{
6 Henry S. Spiegel, El desarrollo del pensamiento económico (Barcelona: Omega, 1984), 77.

7 Una exposición más detallada de estos conceptos puede leerse en Werner Sombart, El burgués. Contribución a la historia espiritual del hombre moderno (Madrid: Alianza Editorial, 1998), 253 y ss.

8 La cultura y lógica del beneficio es propia de un sistema capitalista. El sistema feudal se rige por una lógica diferente.

9 Los bienes muebles: armas, armaduras, trajes, joyas de oro y plata, pedrería, se movían con el guerrero. Véase Pedro Corominas, El sentimiento de la riqueza en Castilla (Madrid: Publicaciones de la Residencia de Estudiantes, 1917), 121.
} 
que era soportado con lo que se conoce como Renta Feudal. Esta era la esencia de aquel sistema que poco tenía que ver con el posterior régimen de separación de factores de producción, en el que tanto el factor trabajo como el factor capital debían ser remunerados, éste último en forma de beneficios.

En las universidades, el pensamiento escolástico era la expresión de ese orden armónico de la sociedad medieval. Para los escolásticos las riquezas habían sido creadas por Dios y entregadas a los hombres para su uso. Debían disfrutarse moderadamente no sólo para ser compartidas con el prójimo, sino también para que quienes las poseían se mantuvieran en la virtud. Santo Tomás de Aquino, siguiendo a Aristóteles, distinguía entre las riquezas naturales, formadas por los bienes que cada cual necesitaba para la satisfacción de sus necesidades vitales y las riquezas artificiales como el dinero, que es un invento del hombre para facilitar el intercambio. ${ }^{10}$ Aunque el Aquinate era consciente de que las necesidades vitales podían ser elásticas, éstas no eran infinitas y, por tanto, tenían un límite. ${ }^{11}$ En cambio, el deseo de las riquezas artificiales sí era infinito y podía llevar a una concupiscencia nunca saciada. En definitiva, las riquezas artificiales eran el origen del pecado de avaricia.

Santo Tomás, hombre de su época, trataba de conciliar las ideas de Aristóteles con la realidad de su tiempo, realidad que hemos descrito como un orden corporativo y estamental. Compartía la idea de que cada persona formaba parte de uno de los cuerpos o estamentos para cumplir su fin, que era la búsqueda de armonía. Según esta concepción, el enriquecimiento no sólo debía producirse únicamente por medios lícitos, sino que también quedaba fijada la medida de la riqueza de la que cada uno había de disponer. Se debía ser tan rico como correspondiera a su rango u orden social. ${ }^{12}$ Buscar más riquezas de las necesarias de acuerdo con la propia posición en la jerarquía social era considerado avaricia, y ésta era pecado mortal. Naturalmente, en los siglos siguientes de pleno desarrollo capitalista, la tradición escolástica fue respondiendo a las nuevas realidades de movilidad social.

10 Tomás de Aquino, Suma de Teología, Parte I-II, Cuestión 2 (Madrid: BAC, 1997), 48.

11 Adolfo Rodríguez Herrera, La riqueza. Historia de una idea (Madrid: Maia Ediciones, 2015), 55.

12 Otra cosa era el proceso de cambio interno que afectaba a las relaciones entre el hombre y Dios. En ese sentido, la vivencia y crecimiento de virtudes personales relacionadas con lo económico, como era el caso de la prudencia, era algo insistentemente defendido por santo Tomás. Esta dimensión moral y personal es tan importante para el desarrollo de la cultura económica que Werner Sombart, profundo conocedor de las ideas tomistas llegó a afirmar lo siguiente: "Estoy convencido de que las teorías de los escolásticos . . . acerca de la riqueza y el lucro, y en especial también sus opiniones acerca de la legitimidad o ilegitimidad moral del cobro de intereses, no sólo no supusieron un obstáculo para el desarrollo del espíritu capitalista, sino que contribuyeron a fortalecerlo y fomentarlo". Werner Sombart, El burgués, op. cit., 252. 
Ya en la plenitud medieval, el desarrollo de la economía dineraria empezó a modificar algunos fundamentos de la economía medieval, aunque el gran cambio vino tras la crisis bajomedieval. Entonces comenzó a variar, sobre todo en la Europa occidental, la naturaleza de la riqueza. ${ }^{13} \mathrm{Al}$ mismo tiempo, comenzaron a cambiar las convicciones morales.

Fue en Italia donde aparecería por primera vez una nueva actitud hacia la riqueza. Ésta, aunque seguía subordinada a la virtud, empezó a ser reconocida como fuente de honor, felicidad y fama. Su adquisición pasó a ser deseable incluso cuando iba más allá de lo estrictamente necesario. Ante esto, el pensamiento escolástico tuvo que intervenir haciendo matices y aclaraciones a la doctrina para atender a los cambios que la nueva realidad imponía y legitimar las nuevas prácticas capitalistas. El afán de ganancias era un fenómeno nuevo en el Renacimiento. Es verdad que siempre había habido individuos arrastrados por el deseo de enriquecimiento; la mayoría de ellos eran magnates y príncipes. La novedad estaba ahora en que nuevos grupos sociales participaban de estas ambiciones y, sobre todo, en la creación de una nueva vía de enriquecimiento a través del comercio. En otras palabras, la concepción medieval de la riqueza fue declinando en los siglos bajomedievales a la par que iba apareciendo otra forma de riqueza — la mercantil—, que se perseguía por vías diferentes a las tradicionales y sobre la cual pronto se empezó a denunciar, por parte de moralistas y teólogos, la desorbitada codicia que provocaba. La ganancia mercantil, sobre todo cuando era mucha, seguía considerándose como algo poco ético. Pero, al mismo tiempo y a pesar de todo, se iba abriendo paso una nueva estimación social por las riquezas así obtenidas.

En la época prerrenacentista, como fase previa al cambio de valoración del fenómeno del enriquecimiento, se produjo el fenómeno del auge del lujo. ${ }^{14} \mathrm{Se}$ diferenciaba del lujo de otras épocas, en primer lugar, por sus amplias dimensiones $\mathrm{y}$, en segundo lugar, porque no se derivaba de los tesoros sino de las mercancías. Entre los siglos XV y XVI se intensificó el ansia de manifestar con ostentación la posesión de grandes riquezas. Se deseaba enriquecerse para manifestarlo públicamente y con ello no tanto ayudar a los más necesitados como ganar fama y honra. De esta forma, la unidad de pensamiento característica de

13 Sobre el desarrollo de la economía dineraria y la cultura del beneficio se puede consultar el libro de José Ignacio Ruiz Rodríguez y Francisco Mochón, El colapso de occidente. Las crisis ante la historia (Barcelona: Ediciones del Serbal, 2001).

14 Lujo es todo gasto o dispendio que está por encima de lo necesario. Puede tomar la forma de derroche o de refinamiento y puede tener una finalidad idealista como dar gloria a Dios con un cáliz de plata o egoísta y materialista. En estas páginas nos referimos al lujo egoísta. Véase Werner Sombart, Lujo y capitalismo (Madrid: Alianza Editorial, 1979), 63. 
la Edad Media comenzó a desvanecerse en el siglo XVI y fue sustituida por una mayor diversidad de opiniones. ${ }^{15}$

Esta diversidad estaba muy conectada con la aparición del Estado moderno y también con la ruptura de la unidad religiosa y la aparición de las Iglesias reformadas. De esta forma, la caridad perdió, especialmente en el campo protestante, la posición central que había mantenido en el sistema económico medieval. Para los reformadores, la salvación se conseguía por la fe, sin la necesidad de las buenas obras. Gradualmente la acción más impersonal de los poderes públicos fue convirtiéndose en la gran proveedora de ayuda para los pobres, no ya en forma de caridad, sino por medio de una legislación más adecuada. ${ }^{16}$ No resulta extraño que, siglos después y tras la revolución industrial, se llegaría a un estadio final en el que se alcanzaría una total secularización del enriquecimiento, afirmando su plena autonomía frente a la moral.

\section{LA APARICIÓN DE LA ECONOMÍA DINERARIA EN ESPAÑA}

En el siglo XVI, la economía dineraria como manifestación visible del incipiente capitalismo mercantil se había convertido en uno de los rasgos distintivos de los comienzos de la Edad Moderna también en España. ${ }^{17}$ En paralelo a la expansión de la economía dineraria, tuvo lugar la creación y desarrollo del Estado moderno. Aunque la presencia del dinero en la actividad económica se remontaba a muchos siglos atrás, lo cierto es que sólo a partir del declive del feudalismo y el surgimiento de la economía de capitalismo mercantil y de incipiente mercado podemos hablar de una verdadera economía dineraria, pues ésta suponía no sólo el empleo habitual y en cantidades significativas de la moneda metálica, sino también la utilización de otras formas de dinero y de instrumentos de cambio y crédito.

Por otra parte, el Estado moderno, representado en España en la Monarquía Hispánica, se enfrentaba no sólo a los profundos cambios económicos impulsados por el descubrimiento y colonización del Nuevo Mundo, sino también a los retos de índole religiosa y, por extensión, de índole cultural derivados de la reforma protestante. En esas coordenadas se desarrolló una renovación del pensamiento cristiano, obra en buena medida de la llamada segunda escolástica, que no era otra que la ya citada escuela fundada por Francisco de Vitoria. Esta

15 Henry S. Spiegel, op. cit., 100.

16 Véase el libro de Bronislaw Geremec, La piedad y la horca (Madrid: Alianza Editorial, 1989).

17 Véase José Antonio Maravall, Estado moderno y mentalidad social, Tomo II (Madrid: Ediciones de la Revista de Occidente, 1972), 58. 
escuela era mucho más que una mera continuación de la escolástica medieval; era tradición más renacimiento y humanismo. ${ }^{18}$

El hombre moderno, encarnado en la figura de mercader, concebía la idea de riqueza por medio de esa representación abstracta del dinero. Mientras que el hombre medieval, caracterizado por la figura del señor feudal, entendía la riqueza en términos de dominio territorial y objetos valiosos que podían ser atesorados, el hombre moderno, gracias a la moneda, tenía un modo nuevo de reconocer y medir la riqueza.

En España la importancia de esta trasformación fue muy notable. Supuso el paso del modelo económico feudal fundamentado en una producción de base agropecuaria orientada, principalmente, a la autosuficiencia y con escaso dinamismo financiero a un nuevo modelo de crecimiento económico fundamentado en la monetización de la economía como era el modelo del capitalismo mercantil. ${ }^{19}$ Por otra parte, de la atomización del régimen monetario de la época feudal, que se correspondía con la fragmentación política, se fue dando paso a un régimen político crecientemente centralizado y unificado. Novedades como la aparición de la inflación a causa de la llegada masiva de plata y oro americano, la desaparición de los pagos en especie y la difusión de los juros eran signos claros de los nuevos tiempos.

En resumen, en Castilla en particular y en toda la Monarquía Hispánica en general, a lo largo del siglo XVI, la circulación del dinero llegó a un volumen nunca visto hasta entonces. La moneda española pasó a ser la más apreciada en el resto del mundo. Todas estas circunstancias fueron objeto de atención no sólo por parte de los escolásticos españoles, comenzando por las lecciones que el propio Francisco de Vitoria impartía desde su cátedra en la Universidad de Salamanca ${ }^{20}$, sino también por predicadores como Tomás de Villanueva.

Es conocido que el crecimiento de la circulación monetaria fue transformando las instituciones sociales en favor de un mercado que se ensanchaba sin parar. Las relaciones económicas se tornaron cada vez más impersonales. Así mismo, la mayor facilidad para acumular riqueza en forma de dinero sin duda propició que el deseo de riqueza creciera a medida que crecía la economía de mercado. También se fueron generalizando los préstamos dinerarios a pesar de

18 Manuel Lázaro Pulido, "Una reflexión sobre la tradición y modernidad en Alfonso de Castro a propósito de la ley", Cauriensia, XIII (2018), 461. Alfonso de Castro, alumno de Francisco de Vitoria, fue como Tomás de Villanueva, un gran predicador.

19 Robert Heilbroner y William Milberg, La evolución de la sociedad económica (México: Prentice Hall, 1999), 26 y ss.

20 José Luis Cendejas, "Justicia, mercado y precio en Francisco de Vitoria", Revista Empresa y Humanismo, XXI.1 (2018), 13. 
la reprobación moral de la usura y la sustitución de los pagos de renta feudal en favor de los pagos salariales de la fuerza de trabajo. Toda esta nueva actividad económica, junto a las transformaciones que se estaban dando en el ejercicio del poder político, influirían en la conformación de una nueva mentalidad y, por tanto, una nueva cultura que en el Siglo de Oro hispánico se traduciría en el choque cultural entre la sociedad caballeresca del honor y la sociedad del beneficio.

El incremento del uso del dinero produjo un gran impacto sobre la sociedad de los siglos XV, XVI y XVII, lo que originó numerosas críticas moralizadoras. Sin embargo, mientras muchos mercaderes utilizaban procedimientos poco éticos para aumentar sus ganancias, otros formulaban consultas a teólogos y a sus propios confesores ante un beneficio que consideraban excesivo. Esto produjo reflexiones y críticas que serían la base de una parte nada desdeñable de la moderna teoría económica. En cualquier caso, lo que resultó difícil de evitar fue que el vicio de la codicia no creciera a la par de la expansión de la economía dineraria.

Desde el momento en que se aceptó que cada uno se esforzara por conseguir el nivel de riquezas que personalmente le correspondía, independientemente de su posición en la jerarquía social, se abrió una amplia oportunidad para la legitimación de la actividad acumuladora de riquezas. A fin de cuentas, todo pasaba a depender del criterio, fácilmente variable, acerca de lo que cada uno juzgara subjetivamente sobre el "estado" que le correspondía en la estructura social. La riqueza por sí misma, como título legítimo de ennoblecimiento al modo que lo son la virtud y el linaje, gradualmente iría pasando a ser principio normalmente aceptado por la doctrina. El burgués (artesano o mercader) pasaba a ser el representante de los nuevos tiempos y de la nueva mentalidad.

José Antonio Maravall afirmaba que según el parecer de muchos observadores de la época había un vicio cardinal, un pecado general que destacaba sobre el resto: la codicia. ${ }^{21} \mathrm{El}$ eterno pecado de la codicia había sido ya duramente atacado durante los siglos medievales. Junto con la condenación del lujo y la vanagloria fue uno de los temas más populares tratados por los predicadores en el otoño de la Edad Media. ${ }^{22}$ Pero en el siglo XVI la codicia, alimentada por las riquezas procedentes del comercio trasatlántico, se generalizaría con redoblada virulencia. Francisco de Vitoria, considerando que las riquezas son un simple medio, advertía que los ricos estaban en un "estado peligroso", es decir, muy expuestos a caer en el pecado, no sólo en el pecado de avaricia, sino en otros

21 José Antonio Maravall, op. cit., 122.

22 Johan Huizinga, El otoño de la Edad Media (Madrid: Alianza Editorial, 1982), 19. 
más ${ }^{23}$ Por otra parte, siguiendo a Tomás de Aquino, recordaba que el apetito de riquezas podía desembocar en avaricia, bien porque se desearan las que exceden al estado y condición propios de cada uno, o bien porque se desearan con ansia las que no lo exceden. ${ }^{24} \mathrm{Y}$ si, por una parte, sería la codicia uno de los vicios que más duramente criticaría Tomás de Villanueva en sus sermones, por otra, las cuestiones morales generadas por ese comercio serían también objeto de análisis por parte de los doctores de la Escuela de Salamanca. ${ }^{25}$

Así pues, a principios de la modernidad, el apetito de riquezas adquirió un carácter más generalizado. Eran muchos más los que entonces aspiraban a enriquecerse. El auge económico de los siglos XV y XVI daba la oportunidad a más gentes de enriquecerse por nuevas vías. Su consecuencia fue una mayor movilidad social que se manifestó en la aparición de ese grupo social intermedio en el que se encontraban menestrales, artesanos, mercaderes, letrados, burócratas, oficiales e incluso labradores ricos.

No obstante, hay que destacar que no todo era nuevo. La mentalidad de los tiempos de la economía tradicional agraria no se rompió. En la mente tradicional agraria se consideraba que si alguno se enriquecía era por apropiarse de lo que era de otro. Esta forma de pensar es comprensible si se tiene en cuenta que, en la economía tradicional, las posibilidades de aumentar la producción eran tan limitadas que difícilmente alguien podía incrementar sus ingresos partiendo sólo de los medios de los que disponía. Pues bien, esa idea de un patrón fijo de producción continuó pesando sobre las mentes de las personas de los siglos XVI y XVII, y contribuyó a moldear su idea de lucro. Por eso, de acuerdo con la conciencia social que se estaba despertando, el afán de lucro de los ricos se traducía para muchos en una mayor opresión del pueblo.

Por otra parte, aquellos hombres enriquecidos gracias a la generalización del uso del dinero, entre los siglos XV y XVI, lograron alcanzar sus aspiraciones de poder y estimación social. Algunos de ellos acabaron haciéndose indispensables para los reyes como prestamistas. Todo eso les dio el prestigio que fue el factor decisivo en su mejora de nivel en la estratificación social. Había nacido un nuevo tipo humano, el burgués, con poder e influencia crecientes y cuya mentalidad y valores se extenderían más allá del mundo de los comerciantes y artesanos. $^{26}$

23 Francisco de Vitoria, Sentencias morales (Barcelona: Ediciones Fe, 1939), 216.

24 Francisco de Vitoria, Comentarios a la Secunda Secundae de Santo Tomás, Tomo V (Salamanca: Biblioteca de Teólogos Españoles, 1935), 257.

25 Cuestiones como la usura, el precio justo, etc. Marjorie Grice-Hutchinson, Ensayos sobre el pensamiento económico en España (Madrid: Alianza Editorial, 1995), 53.

26 Werner Sombart, El burgués..., op. cit., 115. 


\section{BREVE APUNTE SOBRE LA SEMBLANZA DE TOMÁS DE VILLA- NUEVA}

Tomás García Martínez nació en 1486 en Fuenllana, lugar donde se había refugiado su familia al parecer huyendo de una epidemia desatada en Villanueva de los Infantes. ${ }^{27}$ En esta última villa vivió hasta que fue enviado a estudiar a la recién creada Universidad de Alcalá. En esta Universidad salió licenciado en Artes con la primera promoción de estudiantes en $1510 .{ }^{28} \mathrm{Su}$ buena fama y méritos como estudiante habían hecho que el Cardenal Cisneros lo seleccionara para que fuera colegial en el recién inaugurado Colegio Mayor de San Ildefonso. En 1512, con 26 años, alcanzó el grado de maestro en Artes y licenciado en Teología. Su formación, se alimentó no sólo de las enseñanzas y testimonios de los más destacados maestros de su tiempo, sino también de las ideas humanistas que circulaban y que en Alcalá encontraban gran acogida, entre las que se encontraban las ideas de Erasmo. ${ }^{29}$ En 1513 impartió un curso de lógica y filosofía con excelentes resultados. Tal fue la fama docente alcanzada en tan sólo un año que fue invitado a que ocupara la cátedra de filosofía natural en la Universidad de Salamanca.

Sin embargo, acabado el curso académico abandonó la universidad y decidió entrar en la orden de los agustinos, no sin antes haberse informado y haber reflexionado sobre cuál debía ser la mejor opción. El padre Salón nos cuenta que hechas estas diligencias eligió la orden de los agustinos por "su regla santa y ejemplar y observancia razonable" ${ }^{30}$. Allí cambió su apellido García por el de Villanueva. En 1517 profesó y dos años más tarde ya era prior del convento de Salamanca. Tras una etapa de visitador y reformador pasó a ser provincial en 1526. Entre 1520 y 1521 , a instancias de sus superiores comenzó su labor de predicador alcanzando extraordinaria fama y resultados. ${ }^{31} \mathrm{Su}$ experiencia vital y formativa tanto como estudiante de la Universidad de Alcalá como religioso

27 Francisco Javier Campos, Santo Tomás de Villanueva. Universitario, Agustino y Arzobispo en la España del Siglo XVI (Madrid: Ediciones Escurialenses, 2001), 25.

28 No existe unanimidad si fue en 1509 o 1510 cuando Tomás de Villanueva consiguió su licenciatura en Artes. Véase Carolina Lorente Villalba, Tomás García Martínez, Santo Tomás de Villanueva (Alcalá de Henares: Universidad de Alcalá, 1986), 21.

29 Francisco Javier Campos, op. cit., 56.

30 Miguel Bartolomé Salón, Libro de la Vida y Milagros de Santo Tomás de Villanueva, arzobispo de Valencia (Madrid, 1793), 13.

31 Antonio Cañizares Llovera, Santo Tomás de Villanueva. Testigo de la predicación española del siglo XVI (Madrid: Instituto Superior de Pastoral, 1973), 114. 
agustino se trasladó a su labor predicadora, labor propia de un teólogo humanista asentada sobre una sólida base agustiniana. ${ }^{32}$

En 1544, fue llamado a ocupar la complicada sede arzobispal de Valencia. Allí, su labor pastoral dejó una huella indeleble. Cuatro años después de su llegada, en 1548, convocó un sínodo del que salieron unas reformas que serían un adelanto de lo que después se aprobaría en Trento. Además, fundó un seminario diocesano para la formación del clero. Pero, sobre todo, en Valencia, destacó por su ejemplo de caridad y misericordia con los necesitados. Predicó no sólo de palabra, sino también con su propio ejemplo la limosna a los pobres.

Tomás de Villanueva fue no sólo ejemplo adelantado de clérigo y evangelizador de una Iglesia renovada y adaptada a los nuevos tiempos, sino también un modelo de humanista del Renacimiento volcado a la caridad cristiana. Su canonización en 1658 fue un verdadero acto de confirmación y proclamación oficial de la santidad ya reconocida en vida por sus fieles.

\section{LA RIQUEZA EN LOS SERMONES DE TOMÁS DE VILLANUEVA}

La idea de riqueza en Santo Tomás de Villanueva está ligada a su visión de los recursos naturales. Según nuestro santo, siguiendo a los Padres de la Iglesia, Dios dotó a la naturaleza de abundantes recursos naturales para que el hombre no padeciera escasez. Además, los dotó para su utilización en común. Pero el egoísmo humano hizo que, por derecho positivo, los hombres se apropiaran de modo desigual de tales bienes, surgiendo así las desigualdades sociales, los ricos y los pobres. ${ }^{33}$ Por esta razón el hombre justo debía reequilibrar el reparto de los bienes. Así lo expresa en uno de sus sermones:

Porque Dios y la propia naturaleza produjeron un mundo suficiente, más aún, superabundante y rico para los hombres y les tienen puesta una opulenta mesa en los campos, en los ríos, en los árboles, en las aves, en los ganados y los peces, aunque los hombres se multiplicaran por diez y más. Pero la exagerada sobreabundancia en manos de muchos ha engendrado pobreza dentro de un mundo rico. Pues cuando uno lleva a su mesa cincuenta clases de manjares,

32 Javier López de Goicoechea Zabala, "Santo Tomás de Villanueva y el ambiente intelectual de su tiempo", en Francisco Javier Campos (coord.), La Iglesia y el Mundo Hispánico en tiempos de Santo Tomás de Villanueva (1486-1555) (Madrid: Ediciones Escurialenses, 2018), 176.

33 Tomás sigue a san Bernardo en su interpretación de los bienes de la naturaleza. "Pues Dios creó para todos los hombres el cielo y la tierra, todo lo hizo común. Vosotros usurpáis lo superfluo, y porque tenéis mucho, a nosotros nos falta lo necesario". Tomás de Villanueva. Obras Completas, Tomo IX, Conción 398 (Madrid: BAC, 2014), 41. 
obliga a que cincuenta personas no tengan una sola ración que llevarse a la boca. Y cuando otro tiene guardadas cincuenta mudas en el armario, fuerza a que cincuenta no tengan ni una sola que ponerse. Y si uno tiene a reventar de trigo sus graneros, obliga a que otro le falte el pan mar cernido y el chusco de pan de cebada [...]. El hombre debe ser justo frente al prójimo en el reparto de los recursos temporales. Porque, como asegura Ambrosio en su libro sobre "Los deberes", la naturaleza lo hizo todo común, y este mundo no es otra cosa que una especie de heredad perteneciente a todos los hombres, aunque el derecho positivo haya establecido la propiedad privada, daño lugar a lo mío y lo tuyo entre los pueblos. De ahí la explicación de Clemente: El uso de todo lo que hay en el mundo debía de haber sido común a todos, pero la maldad llevó a decir a uno que esto era suyo y a otro que aquello era de él, y de este modo, por derecho de gentes, se consumó el reparto de bienes entre los mortales gracias a la perversión humana. Porque es un principio de justicia que en una heredad común nadie puede apropiarse de lo superfluo con perjuicio de los demás. ¿Pues qué padre que fuera equitativo y justo, si tuviera diez hijos, consentiría de buen grado que uno de ellos se apropiara de toda la heredad o de la mayor parte de ella, dejando a sus hermanos en la miseria ${ }^{34}$

Tomás de Villanueva admite la propiedad privada, pero siempre que ésta sea compartida con los más desfavorecidos. "Pero, aun estando permitido el acceso a la propiedad por derecho positivo, es también de justicia que, si alguno se ha adueñado de los recursos naturales comunes en grandes cantidades, distribuya lo que le sobra a los que lo necesitan". ${ }^{35}$ En este sentido, Tomás de Villanueva comparte plenamente la idea defendida por la Escuela de Salamanca de que el dominio de los bienes obliga a sus propietarios a ayudar a los necesitados no sólo por caridad, como defendía Domingo de Soto, sino también por justicia en caso de necesidad extrema, como defendía Pedro de Aragón. ${ }^{36}$ La conclusión es clara. "Así pues, ésta es la primera parcela de la justicia: que cada cual saque del acervo común que hay en la naturaleza para darlo a los demás, y que no sea demasiado agarrado en quedárselo, y si dentro de lo que permite el derecho tiene excedentes, que sea equitativo y generoso en repartirlos". ${ }^{37}$

34 Tomás de Villanueva. Obras Completas, Tomo IV, Conción 174 (Madrid: BAC, 2012), 285.

35 Tomás de Villanueva, Obras Completas, Tomo IV, Conción 174 (Madrid: BAC, 2012), 285. Sigue así los planteamientos de Tomás de Aquino. Tomás de Aquino, Suma de Teología, Parte II-II, Cuestión 66, a.2 (Madrid: BAC, 1990), 544.

36 Véase José Barrientos García, "El pensamiento económico en la perspectiva filosófico-teológica", en Francisco Gómez Camacho y Ricardo Robledo (Eds.), El pensamiento económico de la Escuela de Salamanca (Salamanca: Ediciones de la Universidad de Salamanca, 1998), 101.

37 Tomás de Villanueva, Obras Completas, Tomo IV, Conción 174 (Madrid: BAC, 2012), 285. 
Nuestro predicador distingue las riquezas temporales de las espirituales. Afirma que las riquezas temporales no son ni buenas ni malas, depende de lo que haga con ellas su dueño, y no deja de reconocer que gracias a Dios hay mucha gente que las emplea en obras buenas. Las riquezas espirituales, como la paciencia, la humildad o la castidad, por su parte, siempre son buenas. ${ }^{38}$ Incluso hay un tercer tipo de riquezas que siempre son malas: las riquezas en pecados.

Las palabras de nuestro santo nos hablan de la ambivalencia de las riquezas. Son un don de Dios, pero también un peligro. Las riquezas son un don de Dios a los hombres, pero si se utilizan bien. El problema es que los ricos no piensan que las riquezas de este mundo sean un regalo recibido; no se consideran distribuidores sino dueños. ${ }^{39}$ Por eso, Tomás clama y alerta contra los peligros de poseer abundantes riquezas. Para ello recurre a numerosas comparaciones. Un ejemplo que repetirá más de una vez es el de las riquezas comparadas con las espinas. ${ }^{40}$

En otro sermón explica cómo obran las riquezas en las conciencias de las personas. Hay gente que escucha en la iglesia la palabra de Dios, pero, tan pronto como ponen el pie fuera, todo lo que acaban de oír se evapora y no sirve de nada a causa de las mil preocupaciones por culpa de los negocios. Por eso da el consejo de que procuren arrancar las espinas de estas preocupaciones, pues “. . . por más que los ricos y voluptuosos lo disimulen y exteriormente parezcan felices, cuando se ven perdidos y han gastado inútilmente el tiempo, ¿qué sentimientos pensáis que experimentan? Con certeza, las que antes les parecían rosas, se darán cuenta de que han sido espinas bien punzantes, y las que antes se les antojaban delicadas flores, ahora las lamentarán como zarzas ensangrentadas. El que se gozaba en medio de todo esto, ¡cómo sufrirá al verse al abrigo de los zarzales!"41.

Tomás de Villanueva para llegar mejor a su audiencia y hacerles comprender el peligro de las riquezas establece diversos razonamientos cargados de imágenes y de analogías. En contra de lo que piensa el pueblo, afirma que éstas no son verdaderas riquezas por tres razones: porque son deleznables, porque son exteriores y porque son efímeras. Son deleznables porque el oro y la plata no son otra cosa que tierra amarilla y pálida. Por eso, gastar la vida entera en

38 Tomás de Villanueva, Obras Completas, Tomo III, Conción 143 (Madrid: BAC, 2011), 649.

39 Tomás de Villanueva, Obras Completas, Tomo V, Conción 193 (Madrid: BAC, 2012), 21.

40 “¿Por qué las riquezas son espinas (a propósito de Lc 8,14)? Sin duda porque, a pesar de que en un momento dado sean atractivas, sin embargo, al cambio del tiempo terminan por dar tortura. Son al principio como una hierba normal, pero cuando se ponen duras, producen pincho". Tomás de Villanueva, Obras Completas, Tomo II, Conción 48 (Madrid: BAC, 2011), 127.

41 Tomás de Villanueva, Obras Completas, Tomo II, Conción 49 (Madrid: BAC, 2011), 145. 
almacenar riquezas es una gran equivocación y una necedad. Decir que son exteriores significa que puede tenerlas cualquiera, por necio y malo que sea. Pone el ejemplo de un hombre de Etiopia que fuera necio y torpe. Con mil arcas llenas de oro, ¿sería mejor persona o más sabio? Con las riquezas no se puede comprar la habilidad, el ingenio, la memoria, la prudencia, la sinceridad, la madurez, la fuerza, la belleza o la magnanimidad. Por último, son temporales y efímeras porque se pierden con suma rapidez. ${ }^{42}$

Si las riquezas no son verdaderas riquezas, tampoco acapararlas es una honra sino una infamia, un vituperio. En primer lugar, porque son viles, como los ojos de los besugos, dignos de burla. Tampoco sirven para tener abundancia de cosas materiales porque al aumentar sus riquezas el hombre se preocupa más por no perderlas y además aumentan sus necesidades. No es rico el que mucho tiene sino el que poco necesita. Las riquezas más bien hacen al hombre indigente. "Pues, el que antes, cuando era pobre, podía contentarse con poco, al crecer en él los bienes de fortuna, creció también el desasosiego, crecieron las necesidades, porque necesita muchas cosas para sí, para sostener su posición social, para los hijos, para la servidumbre, para el boato, y de ese modo se ha hecho más necesitado y le aprietan muchísimo más los gastos. Según Boecio nadie necesita más cosas que el que más tiene". ${ }^{43}$

Para finalizar, Villanueva también predica sobre el valor de las cosas. Distingue, en primer lugar, las cosas que son valiosas en sí, como por ejemplo el oro. Así, el oro es más valioso porque es más precioso que la plata, y la plata más valiosa que el cobre porque es mejor metal. También reconoce que hay cosas que son valiosas en relación con la estima que se tiene de ellas, por ejemplo, las perlas grandes o algunas gemas. En realidad, éstas valen mucho, no por su valor intrínseco, podríamos decir, sino por su estima, es decir, en términos económicos, por su demanda. ${ }^{44}$ Todo ello le sirve para compararlo con el hombre, cuyo valor está en no apreciarse, y su vileza, paradójicamente, es mayor cuanto es mayor su aprecio y estimación. En definitiva, con este ejemplo está llamando a la humildad, a resistirse a esa tendencia antropológica de aspirar a mejorar tanto en la escala social como en el bienestar material y en la posesión de riquezas. Así, "el labrador quiere ser escudero; el escudero soldado; el soldado señor; el señor conde; el conde general; el general rey; el rey emperador" ${ }^{\prime 5}$. Esta ambición, se lamenta, es la que lleva a que los señores abusar de los criados

42 Tomás de Villanueva, Obras Completas, Tomo V, Conción 209 (Madrid: BAC, 2012), 221.

43 Tomás de Villanueva, Obras Completas, Tomo VIII, Conción 305 (Madrid: BAC, 2013), 189.

44 Nótese la coincidencia de esta visión del valor con la teoría del valor de Francisco de Vitoria. Marjorie Grice-Hutchinson, op. cit., 54 y ss.

45 Tomás de Villanueva, Obras Completas, Tomo IX, Conción 406 (Madrid: BAC, 2013), 107. 
y vasallos con cargas desproporcionadas, a que los mercaderes y otros hagan infinidad de contratos falsos, de usuras, de rapiña, etc. El remedio está en conformarse con la posición social en la que se está. Con ello se podrá llevar una vida feliz. Recordando a San Bernardo sentencia que no hay alegría sino en la humildad.

\section{MENTALIDAD Y ACTITUDES DE LOS RICOS}

Tomás de Villanueva no ahorra críticas contra los hombres ricos, pero no por ser ricos sino por el modo como emplean sus riquezas. En un momento de cambio económico y de cambio de actitud social hacia los ricos, los sermones de nuestro santo contra los ricos son una extraordinaria aproximación no sólo al pensamiento de la Iglesia sobre este tema en vísperas de Trento, sino también una vívida descripción de la mentalidad de quienes eran considerados socialmente como ricos y la actitud de éstos hacia el uso de sus riquezas.

Tres caminos hay por los que un pobre puede llegar a ser rico, según nos cuenta el sermón de Villanueva, tres caminos que nos muestran el aquí y ahora de comienzos del siglo XVI. Primero, por la paga y favor de otro. Un ejemplo: el rey nombra comendador a uno que era pobre y éste con una renta de mil ducados anuales se convierte en rico. Segundo, por la habilidad de los negocios. "Uno es pobre y partiendo de los pocos recursos que tiene, procura negociar; es habilidoso, leal en las promesas, trabajador, y en breve tiempo amasa no pocos bienes de fortuna". ${ }^{46} \mathrm{Y}$ tercero, por la suerte. Por ejemplo, cuando alguien excavando en su casa o en el campo encuentra un tesoro. Sea cual sea la vía para el enriquecimiento, no hay nada reprobable en ninguna de las tres. El mal está en el indebido uso de las riquezas, como nos lo recuerda en su comentario sobre la parábola del pobre Lázaro. Para Tomás, el hombre rico que no tiene misericordia con el pobre Lázaro está condenado a perpetrar infinidad de crímenes y a ser arrojado al infierno eterno. Sin embargo, Tomás advierte que “... todas estas miserias no hay que atribuirlas exclusivamente a las riquezas, aunque éstas sean muy peligrosas, sino al mal uso de ellas. Ahí tenéis a Abrahán, que fue rico y ninguno de estos males le ocurrió" ${ }^{47}$. El ejemplo de Abraham nos acerca a la idea de Tomás de Villanueva sobre lo que debía ser un rico ejemplar. Abraham daba limosna y vivía austeramente. "Así debe ser, de modo que el que suspira

46 Tomás de Villanueva, Obras Completas, Tomo III, Conción 102 (Madrid: BAC, 2011), 73.

47 Tomás de Villanueva, Obras Completas, Tomo III, Conción 102 (Madrid: BAC, 2011), 83. 
por el reino, tome del mundo exclusivamente lo necesario para alimentarse y vestirse". 48

Tomás no es nada condescendiente con los ricos. Sus palabras son duras. "Oh ricos inanes del siglo! ¿Por qué os esforzáis en vano por saciar vuestra alma con bienes creados, amasando placeres, renombre, refinamientos, propiedades, criados? ¿No os sucede como a los hidrópicos que, cuanto más bebéis más sed os entra, y cuanto más os infláis, tanto menos os llenáis?". ${ }^{4}$

La parábola del rico y del pobre Lázaro es también una excelente oportunidad para invitar a los ricos a reflexionar sobre su conducta. En un sermón del domingo segundo de Cuaresma, afirma que Cristo no menciona el nombre del rico para mostrar así su rechazo a los ricos. "No nombra Dios sino a lo que tiene ser y existencia. Ser rico, vivir bien, comer bien, no tiene ser; todo pasa.../...Pues no hace caso del rico, porque fue tan olvidado de su salvación, pudiendo obrar bien y no lo hizo, y por esto se condenó tanto como por sus pecados, aunque siendo rico y teniendo las condiciones que tenía, que banqueteaba espléndidamente, que supone que habría otros pecados, aunque no los nombra, pero echa mano del no haber dado al pobre y teniendo tanto aparejo". ${ }^{50}$ Tomás concluye tajantemente: "Ser uno jugador, malo es, carnal, etc., pero tiene remedio. Pero que se halle hombre que no se halle una centella de misericordia, éste ya no hay remedio. Ha llegado a lo último de la maldad"51.

Un descarnado retrato social es la descripción de la desdichada muerte que espera a los ricos. "Están por una parte los hijos, los herederos, que están deseando esa muerte: el día mejor es el de la muerte del bisabuelo y del tatarabuelo. Merodea por otro lado, quejumbrosa, la mujer. Apremia la enfermedad. La conciencia le acusa y no le es posible restituir. Ve que se va al fuego eterno por culpa de sus riquezas que deja en herencia a sus hijos, que hablan mal de él. Siente pesares y de nada le aprovechan; él por un lado restituiría, pero se lo impide el buen nombre, la pompa, los hijos, etc. Entre sollozos, baja desgraciadamente al infierno". ${ }^{2}$

También critica la estima social hacia los ricos. "Hombre, he aquí en qué paran los hombres ricos que mal usan de sus riquezas, que no usan de

48 Tomás de Villanueva, Obras Completas, Tomo III, Conción 102 (Madrid: BAC, 2011), 74. Por otra parte, no eran extraños los casos de mercaderes que llevaban el estilo de vida que predicaba Tomás de Villanueva, como nos recuerda Julio Caro Baroja en Las formas complejas de la vida religiosa. Religión, sociedad y carácter en la España de los siglos XVI y XVII (Madrid: Sarpe, 1985), 391 y ss.

49 Tomás de Villanueva, Obras Completas, Tomo II, Conción 45 (Madrid: BAC, 2011), 75.

50 Tomás de Villanueva, Obras Completas, Tomo IX, Conción 3 (Madrid: BAC, 2014), 427.

51 Tomás de Villanueva, Obras Completas, Tomo IX, Conción 3 (Madrid: BAC, 2014), 427.

52 Tomás de Villanueva, Obras Completas, Tomo III, Conción 103 (Madrid: BAC, 2011), 87. 
misericordia. ¡Qué mal juzgan los hombres que llaman a los ricos bienaventurados! David dice de éstos: ¡Dichoso el pueblo que esto tiene! Mira qué engañados están los hombres que, al que mucho trigo, mucho dinero, tiene por dichoso y beato. ¡Oh necedad humana: ¡las riquezas, faustos, honra, que son camino del infierno, los tengan por buenos! Y la pobreza, que fue alabada por la boca de Cristo, y siéndose esto camino para el cielo, no se haga caso de ella". ${ }^{53}$

En otro sermón hace una curiosa crítica hacia los ricos que aman las riquezas. "Dice que era rico. Unos hay ricos que poseen riquezas; otros que las aman. Poseerlas no es mucho. Abrahán, Job y el mismo Dios son muy ricos. Yo traigo riquezas y gloria. Mas amarlas es malo. Si crecen vuestras riquezas, no les deis el corazón. Tener unos esclavos honra es, mas ser cautivo de ellos, grandísima afrenta. Los que aman las riquezas son esclavos de ellas, pues ellas mandan y tú obedeces". 54

La otra cara de la moneda son los pobres. Tomás insiste una y otra vez que hay que socorrer a los pobres. ${ }^{55}$ También señala los peligros que corren los ricos si no ayudan a los pobres. "Dios, para utilidad de los ricos, hizo que hubiera pobres, para que por estos se salvaran aquellos, pues no tenían abierta ninguna puerta de salvación: porque los ricos no ayunan, no trabajan duro, no sufren persecuciones, no soportan asperezas, no hacen oración, implicados como están en sus negocios" ${ }^{56}$ Continua en el mismo sermón comentando que Dios “. . . creó al rico por el pobre, y al pobre por el rico. Al rico le concedió riquezas para que alimentara al pobre, por eso se las multiplica y acrecienta; al pobre le dio la carestía, las llagas y las penalidades, para que con todo esto moviera a compasión el corazón del rico y éste se salvara. Por tanto, ricos amad a los pobres, hermanos vuestros, redentores vuestros y favorecedores vuestros porque el reino de los cielos es suyo" 57 . Finaliza diciendo que dar limosna no empobrece y que por comer un poco menos para darlo a los pobres es un inconveniente menor. "Si se moderara la comida, tendríamos suficiente para todos y sobraría". ${ }^{58}$

53 Tomás de Villanueva, Obras Completas, Tomo IX, Conción 3 (Madrid: BAC, 2014), 426.

54 Tomás de Villanueva, Obras Completas, Tomo IX, Conción 427 (Madrid: BAC, 2014), 275.

55 Sobre la limosna a los pobres en Tomás de Villanueva véase Clemente López González y José Ignacio Ruiz Rodríguez, "Caridad, misericordia y transferencia voluntaria de renta en la España del Siglo XVI. La predicación y la limosna en Santo Tomás de Villanueva", en Francisco Javier Campos (coord.), La Iglesia y el Mundo Hispánico en tiempos de Santo Tomás de Villanueva (1486-1555) (Madrid: Ediciones Escurialenses, 2018).

56 Tomás de Villanueva, Obras Completas, Tomo V, Conción 199 (Madrid: BAC, 2012$), 91$.

57 Tomás de Villanueva, Obras Completas, Tomo V, Conción 199 (Madrid: BAC, 2012), 91.

58 Tomás de Villanueva, Obras Completas, Tomo V, Conción 199 (Madrid: BAC, 2012), 91. 
Pero es verdad que, como señala en otro sermón, hay ricos que no quieren dar limosna. Por eso exclama: “¡Cuán justamente se quejará el Señor de los ricos el día del juicio! Es como si un padre tuviese un administrador y le ordenase que de sus bienes mantuviera a sus hijos, y llegándose a él los hijos, no quisiera ni vestirlos ni calzarlos, sino que dijera: "Id a vuestro padre a que os vista y calce". ¿No se indignaría el señor contra su proceder? Así es como actúan los ricos, no como el señor, sino como administradores, cuando dicen a los pobres: "Dios os ayude", es decir, id a vuestro padre" 59 .

Para el santo de Villanueva, la raíz de todos los pecados de los ricos es la avaricia. Recoge la definición que da santo Tomás de Aquino sobre la avaricia y la explica: "Santo Tomás dice: "Avaricia es un inmoderado amor de tener". Decimos que es raíz de todos los pecados, porque el hurtar, el trampear, el saltear, el ser usurero y todas las otras que iremos mostrando, todas nacen de la avaricia" ${ }^{\prime 60}$. Siguiendo a la Sagrada Escritura afirma que no hay cosa más abominable que el avaro. Si el pecado de Judas fue grandísimo “. . . aún es mayor el tuyo, avariento, porque Judas vendió a Cristo por treinta dineros, y tú treinta veces por un dinero lo juras, cuanto más que el pecado de Judas de avaricia procedió" ${ }^{\prime 61}$.

La avaricia es algo antinatural. "Mira que Dios se da a sí mismo y todas sus cosas las reparte, y las criaturas hacen lo mismo. El sol te reparte su luz, la tierra sus frutos, etc. Sólo tú, malaventurado, con tu avaricia eres inicuo y no guardas la equidad y la justicia. ¿Qué cosa más inicua que, siendo Dios tan liberal contigo, y dando y comunicándose a ti y todas las criaturas, tú seas avaro con tus prójimos?". ${ }^{62}$

A los ojos de Tomás la avaricia está tan extendida que parece algo normal para sus congéneres. "¿Qué mal tiene que yo ame las riquezas, que mire por mis cosas, que no eche a perder mi patrimonio? ¿Es un pecado tan grande la avaricia como para excluir del cielo al avaro? Que nadie os engañe, hermanos, con semejantes palabras tan seductoras. Adórnalos cuanto quieras, aplica al oro bonitas palabras: la avaricia es un pecado grave y perniciosísimo. El avariento va contra la naturaleza, es un enemigo público, un ladrón disimulado, es un sanguinario [...]. La naturaleza lo hizo todo común: lo mío y lo tuyo nacieron del

59 Tomás de Villanueva, Obras Completas, Tomo IX, Conción 398 (Madrid: BAC, 2014), 41.

60 Tomás de Villanueva, Obras Completas, Tomo IX, Conción 428 (Madrid: BAC, 2014), 281.

61 Tomás de Villanueva, Obras Completas, Tomo IX, Conción 428 (Madrid: BAC, 2014), 281.

62 Tomás de Villanueva, Obras Completas, Tomo IX, Conción 428 (Madrid: BAC, 2014), 281. 
derecho de gentes; sin embargo, el avaro quiere que todo sea suyo, quiere ser dueño de todo, él sólo el amo de los campos, de las viñas y heredades". ${ }^{63}$

De la avaricia no se libran ni los sacerdotes. "¡Oh execrable en grado sumo y necia avaricia la de los sacerdotes! No tienen hijos, ni mujer ni herederos, ¿a qué viene la avaricia?". ${ }^{64}$ El episodio de la expulsión de los mercaderes del templo es utilizado por santo Tomás para criticar la avaricia dentro del clero. Se inspira en la admiración de san Jerónimo por el hecho de que los mercaderes cediesen con tanta facilidad y abandonaran allí las monedas. La explicación según Tomás es fácil: la autoridad de Cristo. Pero hoy en día "las iglesias se han convertido en lonjas de contratación" ${ }^{65}$. También critica que se construyan magníficas iglesias con excesivo gasto y ornato. Continúa predicando contra el enriquecimiento de la Iglesia. "Todas las dignidades, beneficios, rentas, se obtienen previa negociación. Los clérigos se han convertido en negociantes [...] La Iglesia de hoy está plagada de compradores y vendedores de palomas. Todos buscan el lucro. Por él muchos se hacen canónigos, por él muchos se hacen clérigos: para conseguir rentas de altar". ${ }^{66}$

Siguiendo la tradición católica del dominio común de los bienes de la naturaleza, señala en una dura crítica social que el avaro se queda con todo lo que es naturalmente común, que la ruina, el hambre y la necesidad del pueblo proviene del avaro:

¿O es que pensamos que Dios no hizo los campos productivos y suficientes para todos y que, al multiplicarse los hombres, los productos no lleguen para todos? No, de ninguna manera: él lo proveyó con total suficiencia: sólo que la avaricia lo echó a perder todo; pues mientras uno tiene cien mil fanegas en su silo, el otro a la fuerza tiene que pasar hambre, porque al tener uno demasiado, al otro no le llega; si cada cual recogiera lo suficiente, llegaría para todos. En cambio, la sobreabundancia de unos es la pobreza de los otros. Una bien abastecida mesa de aquellos, sus muchos vestidos y de los caros, su potencia en bienes de fortuna, son las causas de la pobreza en el pueblo. ¿Pues qué, no serían suficientes mil carretadas de pescado para todo el pueblo? Pero un solo mayordomo se lleva toda la pesca a la despensa del rico. He ahí la falta y la carestía del pueblo. ¿Acaso no es un enemigo del pueblo el que tanto

63 Tomás de Villanueva, Obras Completas, Tomo II, Conción 84 (Madrid: BAC, 2011), 577.

64 Tomás de Villanueva, Obras Completas, Tomo II, Conción 84 (Madrid: BAC, 2011), 577.

65 Tomás de Villanueva, Obras Completas, Tomo II, Conción 84 (Madrid: BAC, 2011), 571.

66 Tomás de Villanueva, Obras Completas, Tomo II, Conción 84 (Madrid: BAC, 2011), 571. 
daño hace a la comunidad? ¿Y no es ladrón solapado el que pretende quedarse con todo ${ }^{67}$

Tomás señala que Dios hace justicia con esos avaros: les deja sin herederos para que esos bienes se desparramen, se vendan o reviertan a la comunidad, o les da herederos que son pródigos y derrochadores. "Así, vemos con frecuencia que de un padre avaricioso sale un hijo despilfarrador por justa decisión divina: Dios hace, de ese modo, que lo mal amontonado por el padre, lo desparrame el hijo con alguna utilidad". ${ }^{68}$ Otros calificativos para el avaricioso son los de matón, homicida y sanguinario. Su comportamiento es aún más perverso porque no ayudan a los pobres, sino que se aprovechan de ellos. "Paso por alto ahora a los que no sólo no socorren a los necesitados, sino que, además, con fraudes y dolos, y violencia, despluman a los pobres por sus deudas, ejerciendo acciones judiciales con perjuicio de los pobres [...].". 69

Así, no es de extrañar que la avaricia esté castigada con la condenación eterna. Pero la misma avaricia es ya un castigo:

Tienen los avarientos dentro de sí mismos el verdugo de la justicia divina: aquella sed inextinguible, aquella hambre rabiosa, aquella polilla que les roe las entrañas y no les deja descansar. Día y noche se requeman, les desgarran las preocupaciones, las apetencias y los negocios; siempre suspicaces, siempre recelosos; recelan de los de casa, recelan de los extraños, recelan de los hijos, no se fían de nadie; mal vistos por todos, odiosos a todos, serviles, obsesionados por vigilar su dinero. Si las cosas van mal, los atenaza el dolor, se ponen enfermos; si el dinero se agota, se ponen lívidos, están continuamente nerviosos y asustados. Dejando pasar su vida, pierden sus días acaparando para otros. $^{70}$

Para convencer a los avaros de que cambien de actitud emplea incluso argumentos más propios de las creencias populares. "Ea cristiano, mira en ello, que, si supieses que un santo maldice una cosa, que cualquiera que la tocare, sea maldito, y luego le alcanzase la maldición, un fuego de San Antón, otra semejante cosa, ¿quién habría quien osare tocarlo? Pues, avaro, mira las maldiciones". 71

67 Tomás de Villanueva, Obras Completas, Tomo II, Conción 84 (Madrid: BAC, 2011), 577.

68 Tomás de Villanueva, Obras Completas, Tomo II, Conción 84 (Madrid: BAC, 2011), 577.

69 Tomás de Villanueva, Obras Completas, Tomo II, Conción 84 (Madrid: BAC, 2011), 577.

70 Tomás de Villanueva, Obras Completas, Tomo II, Conción 84 (Madrid: BAC, 2011), 577.

71 Tomás de Villanueva, Obras Completas, Tomo IX, Conción 428 (Madrid: BAC, 2014), 281. 
El origen de la avaricia está en la soberbia y la ambición que llevan a querer progresar en la escala social, algo que se ve con recelo desde la mentalidad tradicional:

Indudablemente no en la necesidad, pues la naturaleza se contenta con poco, con lo imprescindible. El hombre necesita poco para vivir, y aunque tenga necesidad de alimentos, como cualquier otro animal, y de ropa para vestirse, se sostiene con escasísima comida y se viste sin problemas. No es la necesidad el motivo de la avaricia, sino la soberbia y la ambición, porque si los hombres intentaran conseguir solamente lo necesario, lo tendrían. Pero tan pronto como empiezan a prosperar económicamente, en seguida cambian su estado social: el empleado se hace comerciante; el comerciante, militar; el militar, magnate: el magnate se hace príncipe. Y así, al crecer la categoría, crece más aún la pompa; y al crecer ésta, crece la avaricia, no para hacer frente a las necesidades, sino para mantener el lujo, para las comidas ostentosas, el vestuario, las casas, la familia, las vajillas, el boato y los dispendios suntuosos. $^{72}$

Tomás relaciona la soberbia con el deseo de riquezas, con el lujo. La soberbia no sólo es un pecado, sino también la raíz de otros pecados. Así, el soberbio es avaricioso porque tiene que mantener una vida de ostentación. Además, la soberbia es un vicio peligroso, entre otras razones, porque es un vicio público. "De la soberbia no nos avergonzamos como de otros defectos. Es más, de ella hasta nos jactamos: adquirimos y nos ponemos lujosos trajes, alardeamos de casas, de vajillas, tapicerías y demás cosas que resaltan el fasto, nos regodeamos públicamente de nuestros cargos, de nuestras riquezas, de nuestro apellido, de las privanzas, de nuestro poderío, y así, cuanto más lejos está de dolernos y abochornarnos este vicio, tanto más lejana está su curación". ${ }^{73}$

Varias son las manifestaciones de la avaricia en el campo de la actividad económica: los engaños y fraudes en el comercio, la usura, los cambios, etc. En concreto con respecto a la usura, siguiendo la tradición de la Iglesia, además de proclamar lo abominable que es, hace la siguiente comparación. "Dime, si fuesen dos hermanos, que tienen igual derecho a una hacienda, si el uno de ellos con engaño quisiese vender de la hacienda que es común a los dos, diríais que le hace muy grande injusticia y sinrazón. Eso haces tú, porque el tiempo común es del pobre y del rico. Pues tú se lo vendes, que por dilación o el anticipar le

72 Tomás de Villanueva, Obras Completas, Tomo II, Conción 84 (Madrid: BAC, 2011), 577.

73 Tomás de Villanueva, Obras Completas, Tomo III, Conción 100 (Madrid: BAC, 2011), 21. 
llevaste más del justo precio; el tiempo vendes. Vendes al fin lo que es común al pobre y a ti, y ¿qué mayor sinrazón?" ${ }^{74}$

Con respecto a los cambios Villanueva apenas se detiene, pero sus palabras merecen ser tenidas en cuenta. "Los que tratáis en cambios no lo hagáis sin consejo. Bien sé que ya los que los tratan son en este caso teólogos, que saben cuándo es lícito y cuándo no. De mi consejo, trata lo menos que pudiereis en ellos". ${ }^{75}$

Sin duda, los ricos a los que se dirige el Santo de los pobres son principalmente los mercaderes, figura a la que nos hemos referido en páginas anteriores. Aunque la crítica a la corrupción de los mercaderes era lugar común de la predicación española, en Tomás de Villanueva vemos un carácter diferente, lejos de las generalizaciones y exageraciones de otros predicadores ${ }^{76}$ Resulta sumamente ilustrativo el juicio que le merece la actividad comercial. Nuestro autor distingue dos tipos de comerciantes: los grandes mercaderes y los comerciantes al por menor. "Hay dos maneras de gente que tratan: Unos en grueso, como son mercaderes, que traen y llevan mercadurías". ${ }^{77}$ Sobre estos grandes mercaderes, el pensamiento de Villanueva coincide con las tesis de la Escuela de Salamanca. ${ }^{78}$ Comerciar es algo tan peligroso moralmente que es necesario recordar a los fieles las condiciones señaladas por santo Tomás de Aquino para que el intercambio fuera lícito. La primera, que la ganancia sea moderada y proporcione lo necesario para vivir dignamente según su condición. Por eso, son reprobables los que procuran comprar lo más barato que pueden y que venden caro. La segunda condición es que el negociar sea con la intención de socorrer a los pobres. Y la tercera condición es que sea con intención de aprovechar a la república contra los que sacan del país las provisiones necesarias. ${ }^{79}$

El segundo tipo de comerciantes es el de los que tratan en menudo. Su peligro está en que pueden incurrir en diferentes formas de engaño en la

74 Tomás de Villanueva, Obras Completas, Tomo IX, Conción 430 (Madrid: BAC, 2014), 297. La usura, por otra parte, fue uno de los temas de ámbito económico más tratados por Francisco de Vitoria. Véase sus comentarios a la Cuestión 77 de la Suma Teológica de santo Tomás. Su texto traducido puede leerse en Contratos y Usura (Pamplona: Eunsa, 2006), 135 y ss.

75 Tomás de Villanueva, Obras Completas, Tomo IX, Conción 433 (Madrid: BAC, 2014), 321.

76 Véase Julio Caro Baroja, op. cit., 383 y ss.

77 Tomás de Villanueva, Obras Completas, Tomo IX, Conción 429 (Madrid: BAC, 2014), 289.

78 Véase Abelardo del Vigo Gutiérrez, "Ética y mercados en la Escuela de Salamanca", en JoséRomán Flecha, Europa, ¿mercado o comunidad? De la Escuela de Salamanca a la Europa del futuro (Salamanca: Publicaciones Universidad Pontificia de Salamanca, 1999), 15.

79 Tomás de Villanueva, Obras Completas, Tomo IX, Conción 429 (Madrid: BAC, 2014), 289. El texto de Tomás de Aquino se encuentra en la Suma de Teología, Parte II-II, Cuestión 77, 600. 
compraventa. "El uno cuando se vende uno por otro, como el vino aguado por puro, las drogas de menor virtud por mayor virtud, el oro falso por puro" ${ }^{\circ 0}$. Es decir, el fraude y la adulteración de los productos. Es engaño "también cuando vendes una cosa ruin por buena, como acaece en si vendes una cabalgadura que tiene alguna enfermedad oculta, como si fuese sana o que tiene más años como de menos, si vendes los esclavos inútiles, que afeitas de tal manera que parecen mejor" ${ }^{\prime 81}$. Otras prácticas fraudulentas que nos presenta nuestro santo reflejan la picaresca de la época: el engaño en los pesos y medidas, o el mojar para que pese más la seda, mezclando azafrán con miel. Contra estos engaños está el remedio de la oración. "Este había de ser tu cuidado, mercader, para no engañar a nadie, luego de mañana encomendar tus negocios a Dios". ${ }^{82}$

La reflexión a la que le lleva todo ello es un tanto pesimista. "Es lástima que ya no saben tratar las gentes sin engañarse. Vio san Juan aquella bestia que dio pregón. Que nadie pueda comprar ni vender si no lleva la marca con el nombre de la fiera o la cifra de su nombre. La bestia es la avaricia: su señal o carácter es el engaño, y su nombre es la mentira. Nadie puede comprar ni vender no teniendo esta señal; porque raro sin mentir ni sin engaño se compra o se vende". ${ }^{83}$

\section{CONCLUSIONES}

Tomás de Villanueva se manifestó siempre en plena comunión con la tradición de la Iglesia con respecto a la propiedad y distribución de la riqueza. $\mathrm{Su}$ perspectiva era moral, pero no por ello menos aguda para captar los recovecos de la actividad económica. Por otra parte, como hombre con una excelente formación humanística, llegó a destacar por su aguda capacidad de observación de la sociedad en la que vivió. Su labor predicadora sobresalió claramente en un momento histórico que ha sido definido como la Edad Dorada de la predicación española. ${ }^{84}$

En su esfuerzo por denunciar los comportamientos que con respecto a la riqueza eran moralmente reprobables y lograr un cambio de conducta, podemos encontrar una fuente muy valiosa para conocer con más profundidad una mentalidad que con sus luces y sombras se iba abriendo camino en los primeros

80 Tomás de Villanueva, Obras Completas, Tomo IX, Conción 429 (Madrid: BAC, 2014), 289.

81 Tomás de Villanueva, Obras Completas, Tomo IX, Conción 429 (Madrid: BAC, 2014), 289.

82 Tomás de Villanueva, Obras Completas, Tomo IX, Conción 429 (Madrid: BAC, 2014), 289.

83 Tomás de Villanueva, Obras Completas, Tomo IX, Conción 429 (Madrid: BAC, 2014), 289.

84 Véase Félix Herrero Salgado, La oratoria sagrada en los siglos XVI y XVII (Madrid: Fundación Universitaria Española, 1996), 118. 
tiempos de la modernidad y que influiría profundamente en la cultura occidental hasta adquirir un nombre propio: la mentalidad burguesa.

Tomás de Villanueva alertó de los peligros de poseer abundantes riquezas, pero, sobre todo, denunció implacablemente la codicia y la avaricia de quienes, beneficiándose del crecimiento económico provocado por la expansión de la economía capitalista, se habían hecho ricos. Nuestro santo no sólo fustigó su actitud renuente a compartir sus ganancias con los más necesitados, sino que también puso en evidencia cómo los comportamientos de estos ricos conducían la mayoría de las veces a llevar una vida lejos de la felicidad a la que aspiraban.

Puede parecer que el trabajo de Villanueva y otros predicadores fue un esfuerzo inútil, pues, al final, el reconocimiento social al que aspiraba este nuevo grupo humano se logró con creces y la avaricia no fue erradicada. Pero tenemos muchas evidencias sobre la influencia real de los predicadores en general y de Tomás de Villanueva en particular. El P. Salón, relatando el impacto de la predicación de Tomás, no deja de mencionar los cambios en la conducta de muchos de los ricos mercaderes que escuchaban a nuestro santo:

En cualquier ciudad o pueblo donde llegaba era cosa notable, luego que predicaba allí este siervo de Dios, el efecto que hacían sus sermones era tan visible que se veían luego convertirse grandes y escandalosos pecadores, remediarse los vicios públicos y de todos los estados acabarse enemistades y bandos antiguos; mercaderes y gente de tratos peligrosos, desengañados y atemorizados con su doctrina, mudar el uso de sus negocios y para asegurar sus conciencias hacer grandes descargos y restituciones; las personas nobles y de estado, hacer manifiesta enmienda de sus vidas, trocando sus paseos, juegos, galas y vanidades en recogimiento, honestidad, limosnas, oración y frecuencia de sacramentos. ${ }^{85}$

La generosidad de la sociedad española del siglo XVI hacia los más desfavorecidos en forma de limosnas, hospitales, obras pías y otras fundaciones es algo que está fuera de toda duda. Por otra parte, la acción social fue también haciéndose cada vez más intensa en los siglos posteriores a nuestro Santo, pasando a ser no sólo obra de los particulares, sino también responsabilidad de los poderes públicos.

Así pues, creemos haber mostrado en estas páginas cómo a partir del pensamiento de santo Tomás de Villanueva se puede observar desde una perspectiva diferente pero complementaria a la de los grandes teólogos y filósofos escolásticos la fractura que a comienzos del siglo XVI se estaba dando en España. 
Fractura entre una mentalidad de tipo tradicional, alimentada por la doctrina de la Iglesia y renovada por el pensamiento escolástico, y unas actitudes y conductas por parte de quienes, beneficiándose de las oportunidades que generaba la expansión del capitalismo mercantil, deseaban no sólo encontrar reconocimiento social a sus acciones sino también cambiar ese mismo orden social.

\section{REFERENCIAS BIBLIOGRÁFICAS}

Aquino, Tomás de. Suma de Teología. Parte I-II. Madrid: BAC, 1997.

-. Suma de Teología. Parte II-II. Madrid: BAC, 1990.

Berger, Peter L. "Observaciones acerca de la cultura económica". Estudios Públicos, 40, 1990, 11-30.

Barrientos García, José. "El pensamiento económico en la perspectiva filosófico-teológica". En El pensamiento económico de la Escuela de Salamanca, editado por Francisco Gómez Camacho y Ricardo Robledo, 93-122. Salamanca: Ediciones de la Universidad de Salamanca, 1998.

Campos, Francisco Javier. Santo Tomás de Villanueva. Universitario, Agustino y Arzobispo en la España del siglo XVI. Madrid: Ediciones Escurialenses, 2001.

Cañizares Llovera, Antonio. Santo Tomás de Villanueva. Testigo de la predicación española del siglo XVI. Madrid: Instituto Superior de Pastoral, 1973.

Caro Baroja, Julio. Las formas complejas de la vida religiosa. Religión, sociedad y carácter en la España de los siglos XVI y XVII. Madrid: Sarpe, 1985.

Cendejas, José Luis. "Justicia, mercado y precio en Francisco de Vitoria". Revista Empresa y Humanismo, XXI.1 (2018): 9-37.

Corominas, Pedro. El sentimiento de la riqueza en Castilla. Madrid: Publicaciones de la Residencia de Estudiantes, 1917.

Geremec, Bronislaw. La piedad y la horca. Madrid: Alianza Editorial, 1989.

Grice-Hutchinson, Marjorie. Ensayos sobre el pensamiento económico en España. Madrid: Alianza Editorial, 1995.

Heilbroner, Robert y Milberg, William. La evolución de la sociedad económica. México: Prentice Hall, 1999.

Herrero Salgado, Félix. La oratoria española en los siglos XVI y XVII. Madrid: Fundación Universitaria Española, 1996.

Herrero Salgado, Félix y Núñez Beltrán, Miguel Ángel. Predicadores y sermones en España (Siglos XVI-XX). Madrid: Fundación Universitaria Española, 2014.

Huizinga, Johan. El otoño de la Edad Media. Madrid: Alianza Editorial, 1982. 
Lázaro Pulido, Manuel. "Una reflexión sobre la tradición y modernidad en Alfonso de Castro a propósito de la ley", Cauriensia, XIII (2018): 459-478.

López de Goicoechea Zabala, Javier. "Santo Tomás de Villanueva y el ambiente intelectual de su tiempo". En La Iglesia y el Mundo Hispánico en tiempos de Santo Tomás de Villanueva (1486-1555), coordinado por Francisco Javier Campos, 169-196. Madrid: Ediciones Escurialenses, 2018.

López González, Clemente y Ruiz Rodríguez, José Ignacio. "Caridad, misericordia y transferencia voluntaria de renta en la España del Siglo XVI. La predicación y la limosna en Santo Tomás de Villanueva". En La Iglesia y el Mundo Hispánico en tiempos de Santo Tomás de Villanueva (1486-1555), coordinado por Francisco Javier Campos, 83-112. Madrid: Ediciones Escurialenses, 2018.

Lorente Villalba, Carolina. Tomás García Martínez, Santo Tomás de Villanueva. Alcalá de Henares: Universidad de Alcalá, 1986.

Maravall, José Antonio. Estado moderno y mentalidad social, Tomo II. Madrid: Ediciones de la Revista de Occidente, 1972.

Pena González, Miguel Anxo. "Aproximación histórica al concepto Escuela de Salamanca”, Salmanticensis, 52 (2005): 69-119.

Rodríguez Herrera, Adolfo. La riqueza. Historia de una idea. Madrid: Maia Ediciones, 2015.

Ruiz Rodríguez, José Ignacio y Mochón, Francisco. El colapso de Occidente. La crisis ante la historia. Barcelona: Ediciones del Serbal, 2011.

Salón, Miguel Bartolomé. Libro de la Vida y Milagros de Santo Tomás de Villanueva, arzobispo de Valencia. Madrid, 1793.

Sombart, Werner. Lujo y capitalismo. Madrid: Alianza Editorial, 1979.

- El burgués. Contribución a la historia espiritual del hombre económico moderno. Madrid: Alianza Editorial, 1998.

Spiegel, Henry S. El desarrollo del pensamiento económico. Barcelona: Omega, 1984.

Vigo Gutiérrez, Abelardo del. "Ética y mercados en la Escuela de Salamanca". En Europa, ¿mercado o comunidad? De la Escuela de Salamanca a la Europa del futuro, editado por José-Román Flecha, 13-24. Salamanca: Publicaciones Universidad Pontificia de Salamanca, 1999.

Villanueva, Tomás de. Obras Completas, Tomos I-X. Madrid: BAC, 2010-2015. Vitoria, Francisco de. Comentarios a la Secunda Secundae de Santo Tomás. Tomo V. Edición de Vicente Beltrán de Heredia. Salamanca: Biblioteca de Teólogos Españoles, 1935.

-. Contratos y usura. Introducción, traducción y notas de $\mathrm{M}^{\mathrm{a}}$ Idoya Zorroza. Pamplona: Eunsa, 2006. 
-. Sentencias morales. Selección y prólogo de Luis Getino. Barcelona: Ediciones Fe, 1939.

Clemente López González Facultad de Ciencia Jurídicas y Empresariales Universidad Francisco de Vitoria Carretera Pozuelo - Majadahonda, Km. 1,8 28223 Pozuelo de Alarcón, Madrid (España) https://orcid.org/0000-0002-7974-3661.

José Ignacio Ruiz Rodríguez Departamento de Historia y Filosofía Facultad de Filosofía y Documentación C/ Colegios, 2 28801 Alcalá de Henares, Madrid (España) https://orcid.org/0000-0002-8358-8211 